uppermost portion of the left motor area. The outer surface of the skull was intact. 'The opening of the lacerated dura was enlarged, the coagulated blood removed and the cortex exposed. 'The latter's surface was found intact; no laceration could be scen.

Result.-The pationt gradually improved and finally recovered. The mental liebetude completely disappeared. During the first two days the knec-jerk remained slightly exaggerateil, but on the fourtl diy bocame normal. On the sixth day, the paraloxic reflex beaime fainter and on the twelfth day after the operation it coulil no more be elicited. It was interesting to observe its gradual diminution and disappearance and it was also interesting to notice its conspicuous presence on the morning before the operation and its gradual oblitration after the operation. The patient was subsequently secu by me several times during a period of two months and at no time could I detect the presence of an abnormal knee-jerk or of the paradoxic reflex.

This case, I belicre, is the most striking illustration of my contention concerning the practical value of the reflex. Added to the first two cases pullished in 1906 and $190 \%, 3$ it fumishes decisive anatomic proofs for the a priori deductions made from clinical observations. The reflex has its diagnostic value and deserves a place in nosology of the nerrous system.

In conclusion, I may mention that a systematic inrestigation was made by me in 800 individuals free from diseases of the nervous srstem, also in 250 cases of functional nerrous diseases and at no time was extension of the toes elicited by the method employed bx me for the detertion of the paradoxic reflex.

1430 Pine street.

\section{THE AUTOLYSIS OF THE CRYSTALLINE LENS}

\section{A PRELIMINARY RePORT}

\section{A. CLAPP, M.D.} B.ATIMIORE:

In the study of trammatic cataract and the needling opreration, 1 was struck with the very scant description of the manner in which the lens becomes opaque and the rauses for its opacity and final absorption.

Parsons ${ }^{1}$ states that after exposurc of the lens fihers to the action of the aqueous they swoll up, become opaque, protrude through the capsular wound, and finally break up in the uslat manner, absorption being largely due to the lenkocrtes, which become swollen and filled with granules.

Schlösser ${ }^{2}(188 \%)$ in an article on traumatie cataract, and Schirme:" (1889) have studied the microseopic changes rery thomolngly, but without throwing much light on the cause of these changes.

Fuchs states that the fibers swell up and becone opaque through absorption of water ; some are broken off and drop into the anterior chamber and are absorbed. But he also says that concussion without rupture of the (apsule may cause the derclopment of complete opacity of the lens. IHe, howerer, fails to state just why this occurs.

De Schweinits says that the opacity and liquefaction are explained by the action of the sodium chlorid of the aqueous on the globulin of the lens substance, as globulin is normally soluble in weak sodium chlorid solution.

1. Parsons: The I'athology of the Eye, 1904.

2. Schlösser : Experimental Studies on 'Traumatic Cataract, $18 \times 7$.

3. Schirnel : Arch. f. Ophth., 1889)

4. Fuchs: 'Text-Book of Ophthalmology, 1908.

fir De Schweinitz: Discases of the Eye, 1910.
This theory was, I think, first suggested by Marcus Gumn in 1899 in the Ophthalmic Review.

In further search of the literature on the subject I lave found no elaboration.

In order to inderstand the subject it is necessary to have a knowledge of the chemistry of both the aqueous ant the crystalline lens.

Halliburton gives the composition of calves' aqueous as in 'Table 1.

\section{TABIE 1.-COMIOSITION OF THE AQUEOUS}

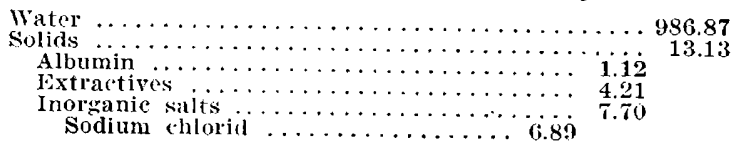

'Thus it will be seen that it consists practically of normal saline solution with a trace of albumin and cxtractives.

The composition of the lens as given by Neumeister is set forth in Table 2.

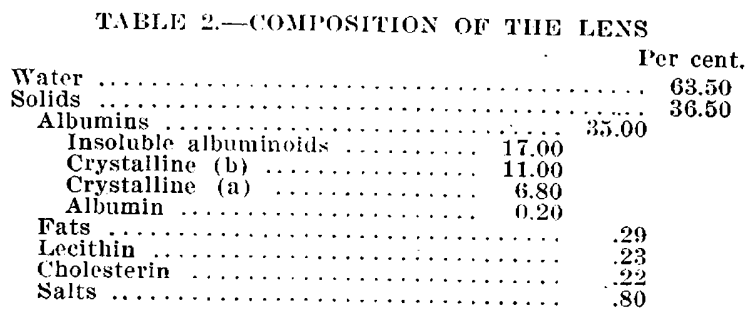

It will be scen that the lens contains 3.5 per cent. of protein, the highest protein percentage of any tissue of the body. Of this 35 per cent. protein, 17 per cent. is in the form of an insoluble albuminoid which is insoluble in normal saline or water.

It is a true albumin and constitutes most of the lens fibers, its amount increasing from without inward in accorlance with the increasing age of the lens fibers. The remaining protein consists of a smali amount of serum albumin and two vitellins which are soluble in dilute saline or in water.

If these analyses are correct, we have great difficulties in explaining the foregoing theories.

I can hardly agree with Parsons' statement that most of these fibers are carried off by the leukocytes. In the first place, if there is no infection there should not be many polymorphonuclear leukocytes about, as they occur chiefly in inflammatory troubles; and secondly, it would not explain the traumatic cataract with absorption in those cases of concussion without rupture of the capsule.

Fuchs scems to keep on the safe side by simply stating that the fibers become opaque and are finally absorbed, and by giving no explanation for the cause of the concussion cataract.

De Schweinitz's promulgation of Marcus Gunn's suggestion is, if the chemistry be correct, entirely untenable. To be sure the (a) and (b) crystalline bodies would be dissolved out either by water or the aqueous, but the insoluble albuminoid which makes up the greater portion of the protein, and which occurs chiefly in the lens fibers, is insoluble in either the water or the saline.

It is easily seen from a study of the chemistry of the lens why it becomes opaque either after injury with the entrance of aqueous or even from concussion. In case of rupture of the capsule and entrance of the aqueous there would occur an immediate precipitation of this insoluble albuminoid, while the remaining portions 
would be soluble and could be carried off by the circulattion of the aqueous. In cases of concussion without rupture of the capsule, there undoubtedly occurs some rupture of the lens fibers, and then this insoluble albuminoid is brought into contact with the lens lymph which acts in the same manner as the aqueous in pre(-ipitating the albuminoid.

But what is the factor which causes the solution of this albuminoid so that it can pass off in the circulation?

As we have known for several years that most of the organs and tissues of the borly show autolytic activity under favorable conclitions, we believe that this autoIrtic action also takes place in the lens sulstance after the rupture and breaking up of the lens fibers. There is also quite a possibility that there is some ferment in the acpeous which hastens this action. It is more probable, however, that the aqueous serves its chief purpose in arrying oft the liquefied lens substance. Therefore, in order cither to prove or to disprove our theories, the following experiments were carried out, using calves' res as the working material. They were enucleated at the alattoir and transported immediately to the laboratorv and lept on ice until used, which was always within six hours after enucleation.

Nov. 1, 1909, I received thirty calves' eyes and drew off the aqueous wilh a sterile iypodermic needle. The lenses were removed and macerated, then diluted with normal saline solution, so as to make a dilute solution of lens albumin of about 1 per cent. 'This was agitated so as to make as nearly a homowneous suspension of the insoluble portions as possible, and 5 c.e. were neasured into three test-tubes. To the first wore added 5 c.c. of the aqueous solution. To the second were anded 5 c.c. of the boiled aqueous. To the third were added i) c.c. of normal saline solution. These were stoppered tightly and placed in an incubator at $36 \mathrm{C}$. and allowed to remain for twenty-two days.

Chloroform and toluol were added to prevent bacterial action. Jhey were then removel and the amount of soluble nitrogen was determined in arch tube. They were precipitated by the action of heat and acetic acid, filtered and washed, and the amount of nitrogen determined in the filtrate by Kjeldahl's method, whieh consists of digesting with concentrated sulphuric acid and copper sulphate and distilling the remains, after rendering strongly alkaline, into a measured amount of tenthBormal sulphurje acid and titrating the excess of the acid.

By this procedure I obtained the results shown in Table 3.

TARIE 3

$$
\begin{aligned}
& \text { No. 1.-5 c.c. lens albumin } \\
& 5 \text { c.e. aquenens } \\
& =2.1675 \text { c.e. } \mathrm{N} / 10 \mathrm{H}_{2} \mathrm{SO}_{4} \\
& \text { No. 2.-5 c.c. fens albumin }
\end{aligned}
$$

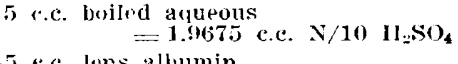

$$
\begin{aligned}
& \text { No. 3.-5 e.c. lons albumin } \\
& =0.8175 \text { c.c. } \mathrm{N} / 10 \mathrm{Il}_{2} \mathrm{SO}_{4}
\end{aligned}
$$

By this experinent it appears that the boiling of the acueous has some inhibitory effect on its action on the lens alloumin. It also appears that the aqueous either increases this process, or at least hastens it, because as will be scen, there is over twice as much soluble nitrogen in No. 1, which was combined with the umboiled aqueous, as in No. 3, in which there was only salt solution.

On account of lack of aqueous these experiments were not clone with a control, so that the results are open to more (ritirism tluan they would otherwise be. All other experiments along similar lines with equal quantities of lens and aglicons were spoiled so that I lack confirmatory evidence, which I hope I shall be able to supply shortly.

Nov. 8, 1909, I started another series in the following manner:
Twenty calves' lenses were macerated with the accompanying aqueous, 15 c.c. and the whole made up to 500 c.c. with normal salt solution. Chloroform and toluol were added to prevent bacterial changes.

The preparation was then placed in a tightly stoppered tlask and set in an inculator at $36 \mathrm{C}$. , a mensured amount being removed from time to time and the soluble nitrogen being retermined by precipitating with heat and acetic acid and doing

\begin{tabular}{|c|c|}
\hline Date & 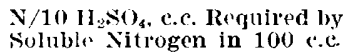 \\
\hline $11 / 8 / 09$ & $\ldots \ldots \ldots \ldots 4.8000$ \\
\hline $\begin{array}{l}11 / 16 / 09 \\
11 / 2: / 09\end{array}$ & $\begin{array}{l}2.6750 \\
3.5875\end{array}$ \\
\hline $11 / 30 / 09$ & 4.3375 \\
\hline $12 / 709$ & 3.9625 \\
\hline $15 / 09$ & 3.8375 \\
\hline $1 / 5 / 10$ & 4.0875 \\
\hline $\begin{array}{l}2 / 17 / 10 \\
3 / 17 / 10\end{array}$ & 5 \\
\hline $5 / 23 / 10$ & 8.1175 \\
\hline $10 / 25 / 10$ & $\ldots \ldots \ldots 8.9125$ \\
\hline
\end{tabular}
the Kjoldahl test on the filtrates as in the preceding exporiment, with results given in Jable 4 .

TABLE 4.-VARIATIONS IX NOATLE NITROGLN AS IDTERMINEI BY IIEAT ANI ACETIC ACID

The autolytic matrial was now set at room temperature until October 25 .

As will be seen by a glance at these figures there was a considerable lessening of the soluble nitrogen immeniately after starting the process, after which, with practically one exception, a gradual rise until the quantity was nearly twice that of the original amount.

This initial decrease could be explained by the possibility of a reversible action of the ferment and a building 11) instead of a tearing lown, as is seen in some other instances in physiologic chemistry, notably some of the fat ferments.

The influence of the small amount of aqueous in this experiment was, I believe, almost mil, as I will show in the following experiment a similar picture without the presence of any aqueous.

Xov. 18, ]!0!), twenty calves' Jenses were macerated and male up to 500 c.c. with normal saline solution. Chloroform and toluol were added and placel in an incubator at 36 (., being placed in a tightly stoppered flask to prevent evaporation; 20 c.c. was removed from time to time and the precipitable protein removed by Abeles' method, which is as follows:

Fifty e.e. of absolute alcohol, $2.5 \mathrm{gm}$. zinc acetate, and 50 c.c. of the fluid are mixed and allowed to stand ten minutes and then filtered through a filter moistened with alcohol; the residue is rubbed up in a mortar several times and filtered; the rine is frecipitated with 20 per cent. sodium earbonate solution; this is filtered, acidulated with acetic acid, evaporated and a Kjeldabl test done on the filtrate.

This method is claimed to give more accurate jesults than the heat and acetic acid method. By the use of this method I obtainel the following results:

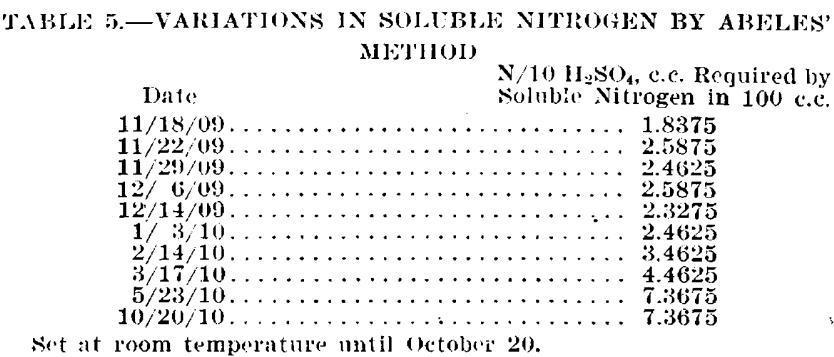

In this and the preceding series, double estimations were made and when there was a variation the average of the results were taken.

It will be seen, as in the precelling experiment, that there was very little change for the first thee months 
and then there was such a pronounecd change that one could hardly believe it to be accidental.

Here, as in the precedine series, there was little or no action while the material was at room temperature. from Mar to Octolyer, 1910.

Whether this was due to the slightly lowered temperature I cannot sav. Neither can I sar whether the increase in soluble nitrogen would have continued, as I hat insufficient material to continue the experiment.

'The truptophan reaction was negative in hoth of these last experiments, on I)ec. 11, 1910, showing that there was no very active ferment at work which would split up the andido-acids. Botle preparations were tested for bacterial gronth Dee. 12, 1910, by inoculating slant agar, with negative results.

If further investigation confirms my preliminary findings, then I think that it is safe to sar that when the lens fibers are broken up they undergo autolytic. changes. Whether this is increased by the action of some specific enzrme in the arpuens or whether it is dne entirely to autolysis. it is difficult to say. If this be a ferment. then what jis its source? Is it produced through the breaking up of the lens fibers. or is it derived from the circulating lymph? These questions I cannot answer.

These results coinride nicely with the facts as we know them. The lens of the young is much more easily liquefied and carried off, from the fact that there is less of the insoluble allouminoid present and the enzrnes are all very active. In the aged, on the contrary, there is a much larger anount of the insoluble portion and all of the enzrmes are relatively woak.

In closing 1 wish to thank Dr. E. T. Whitney for his many kind sugrestions, and for the use of his private laboratory and apparatus at the Baltimore Medical College.

412 Cathedral Street.

\section{TESTS OF THE VIRULESCE OF IOIPH- TTIERIA B.ICIILT *}

\section{B. I. ARMS. M.D., AND E. MARION WADE, B.A}

Bacterioloxical taboratory of the Boston Board of Ifealth Bostox

Many times the labnatory worker is recuested to tost the rirulence of diphtheria harilli, especially in rases running for a lone time, or in those oremring in inctitutions, and as we have had many interestiner results from these tests we present some of them for consideration.

Our laboratory las always made virulence tests, on request either from the Board of Health or from the attending phrsician, the procedure being to isolate either by the streak-out mothod or surface seeding. For the former a series of eight or ten tubes is used, a fresh tulse being inoculated from the incubated one; then, after sterilizing the needle, another from the freshly inoculated one, and so on through the series, taking from the first tube to the second. from the second to the third, ste. sterilizing the needle after inoculating each tube. In that way isolated colonies may be found on the later ones, as of course a smaller number of organisms is carried over cach time. For the surface-seeding method five tubes are used, those being selected which contain a

* Read before thr Socicty of American Bacteriologists, at Ithaca. N. $\mathbf{x}$, Dec. $28-30,1910$. fair amount of water of rondensation. This is rubled over the surface in order to insure an even distribution at the proper time. Inoculation is made. directly into the water of condensation of the first tuhe. the needle is sterilized, and a loopful is carried into the water in the second tube: stcrilization and inoculation being repeated throughout the scries. The tubes are then laid down at the proper angle to cause the water to flow over the surface of the serum and allowed to remain for from two to fire minutes, when they are taken up carefully and put into the incubator in the upright position. After inculation isolated colonies are "fished" and planted on serum and in sugar-free broth, and a microscopic examination is also made.

If there is no particular need for haste, or, in rases in which the organisms are verv fow, we sometimes make serum and microscopic examinations only, inoculating several colonies one above the other on a single scrum tube, therely making a great saving in the amount of media used; for many times we "fish" from twenty to forty colonies from a single series, especially from long-standing cases, the broths being made from the serum tubes after incubation.

These are incubated for forty-eight hours and pigs inoculated subcutaneous]y, using 0.5 per cent. of the body weight. The reaction may be local or general, or, as is usual in positive cases, both. and is generally present the following day, although a negative report is never given until forty-eight hours after the inoculation.

The virulence of morphologically typical diplitheria bacilli (Wesbrook's A C D) varies, not only in different cases but in different strains from the same case, from thinse absolutely non-virulent to those which cause death within thirty-six hours.

This was first brought to our notice in December, 1906. when a series of six pigs was inoculated, each witl a different strain isolated from the same release culture.

In order to hasten the report one strain was inoculated at the end of the twenty-four hours and this proved virulent, the pig heing so nearly dead on the second day that it was chloroformed.

The other fire strains were all incubated for fortyeight liours and the difference in their virulence was very marked:

1. This was the ping previously mentioned.

2. This pig died on the eighth, day, the reaction being local and general.

3. This pig died on the second day.

4. This pig showed a very slight local reaction on the second day, which increased slightly during the next week, but at no time was there a marked reaction. This pig was kept. under observation for six weeks, complete recovery resulting.

5. This pig died on the ninth day.

6. In this instance there was a slight local reaction at the end of twenty-four hours which became more marked daily for some time and there was a slough surrounding the point of inoculation, the pig dying at the end of six weeks.

All of the above strains, grown fifteen hours on serum, were of Wesbrook's A A1 types. A rush of work prevented further tests at this time but.an interesting problem had heen presented.

Nov. 9, 1907, three pigs were inoculated with three strains isolated from a release culture, two dving within forty-eight hours and the other showing no.symptoms; in order to rule out a possible difference in the resistance of the pigs we kept the cultures and eleven days later inoculated the surviving pig, and a new one to serve as a control, with the avirulent strain and at the 